\title{
Slow exchange of bidentate ligands between rhodium(I) complexes: evidence of both neutral and anionic ligand exchange
}

\begin{abstract}
Si Chen, ${ }^{[a, b]}$ Eric Manoury ${ }^{[a, b]}$ and Rinaldo Poli* ${ }^{* a, b, c]}$
Abstract: The phosphine double exchange process involving $[\mathrm{RhCl}(\mathrm{COD})(\mathrm{TPP})]$ and $[\mathrm{Rh}(\mathrm{acac})(\mathrm{CO})(\mathrm{TMOPP})]\left(\mathrm{TPP}=\mathrm{PPh}_{3}\right.$, TMOPP $\left.=\mathrm{P}\left(\mathrm{C}_{6} \mathrm{H}_{4}-4-\mathrm{OMe}\right)_{3}\right)$ to yield $[\mathrm{RhCl}(\mathrm{COD})(\mathrm{TMOPP})]$ and $[\mathrm{Rh}(\mathrm{acac})(\mathrm{CO})(\mathrm{TPP})]$ is very rapid but is followed by a much slower process where the bidentate ligands are exchanged to yield $[\mathrm{Rh}(\mathrm{acac})(\mathrm{COD})]$ and a mixture of $\left[\mathrm{RhCl}(\mathrm{CO})(\mathrm{TPP})_{2}\right]$, $\left[\mathrm{RhCl}(\mathrm{CO})(\mathrm{TMOPP})_{2}\right]$ and $[\mathrm{RhCl}(\mathrm{CO})(\mathrm{TPP})(\mathrm{TMOPP})]$. The exchange involving $[\mathrm{RhCl}(\mathrm{COD})(\mathrm{L})]$ and $[\mathrm{Rh}(\mathrm{acac})(\mathrm{CO})(\mathrm{L})]$ yields $[\mathrm{Rh}(\mathrm{acac})(\mathrm{COD})]$ and $\left[\mathrm{RhCl}(\mathrm{CO})(\mathrm{L})_{2}\right]$, the reaction being much faster when $L=$ TPP than when $L=$ TMOPP. The mixed-metal system comprising $[\mathrm{IrCl}(\mathrm{COD})(\mathrm{TPP})]$ and $[\mathrm{Rh}(\mathrm{acac})(\mathrm{CO})(\mathrm{TPP})]$ yields all four complexes $[\mathrm{M}(\mathrm{acac})(\mathrm{COD})]$ and $\left[\mathrm{MCl}(\mathrm{CO})(\mathrm{TPP})_{2}\right]$ where $\mathrm{M}=\mathrm{Rh}$ and Ir. This illustrates that both a neutral ligand exchange and an anionic ligand exchange occur. Possible pathways for these processes are discussed.
\end{abstract}

\section{Introduction}

The mechanism of ligand exchange processes has long been a topic of interest for coordination chemists. ${ }^{[1-3]}$ Ligand exchange dynamics is of importance in all catalytic processes, whether industrially or biologically relevant. Ligand exchange in square planar $\mathrm{d}^{8}$ complexes has occupied a dominant position, given the large number of catalytic reactions promoted by $\mathrm{d}^{8}$ metal centers such as Rh', Ir', Ni", Pd", Pt" and Au'll. Most of the ligand exchange investigations have dealt with $\mathrm{Pt}$ " complexes, given their relative inertness and stereochemical stability that bring the reactions within a suitable half-live range for convenient studies by classical mixing and monitoring methods. ${ }^{[3]}$

Ligand exchange in $\mathrm{Rh}^{\mathrm{l}}$ complexes has been studied to a lesser extent. It is nevertheless well appreciated that it occurs predominantly via an associative pathway, like for the other $d^{8}$ systems and as anticipated by the "16 and 18 electron" rule. ${ }^{[4]}$ For instance, NMR investigations on $[\mathrm{RhCl}(\mathrm{COD})(\mathrm{L})](\mathrm{COD}=1,5$ cyclooctadiene; $\mathrm{L}=\mathrm{PPh}_{3}, \mathrm{AsPh}_{3}$ ) in the presence of excess $\mathrm{L}$ have revealed very fast (signal coalescence on the NMR timescale) and associative (first order in free L) ligand exchange. Furthermore, fast exchange still occurs in the absence of free $L$ through monomer-monomer interactions. ${ }^{[5]} A$ very rapid ligand

[a] Ms. S. Chen, Dr. E. Manoury, Prof. R. Poli

CNRS, LCC (Laboratoire de Chimie de Coordination)

205 route de Narbonne, BP 44099

F-31077, Toulouse Cedex 4, France

E-mail: rinaldo.poli@lcc-toulouse.fr,

http://www.lcc-toulouse.fr/equipe g/pages/poli/index.htm

[b] Université de Toulouse, UPS, INPT

F-31077, Toulouse Cedex 4, France

[c] Institut Universitaire de France, 103

bd Saint-Michel, 75005, Paris, France

Supporting information for this article is given via a link at the end of the document. exchange process was also observed for $\left[\mathrm{Rh}(\mathrm{acac})(\mathrm{CO})\left(\mathrm{PPh}_{3}\right)\right]$ (acac = acetylacetonate) with free $\mathrm{PPh}_{3} \cdot{ }^{\left[{ }^{6]}\right.}$

We have recently embarked in an investigation of the hydroformylation reaction catalyzed by $\mathrm{Rh}$ complexes supported on precise phosphine-functionalized macromolecular architectures built by controlled radical polymerization. ${ }^{[7-9]}$ These polymers were obtained by copolymerization of styrene and 4-diphenylphosphinostyrene (DPPS); they can be considered as having polystyrene-linked triphenylphosphine ligands. In relation with these catalytic studies, we have explored double exchange processes where one phosphine ligand $\left(P_{1}\right)$ bonded to one type of $\mathrm{Rh}$ complex $\left(\mathrm{Rh}_{1}\right)$ exchanges with a second phosphine ligand $\left(P_{2}\right)$ bonded to a second type of $R h$ complex $\left(R h_{2}\right)$, see eq. 1 .

$$
R h_{1}-P_{1}+R h_{2}-P_{2} \rightleftarrows R h_{1}-P_{2}+R h_{2}-P_{1}
$$

This double exchange process on polymer-supported phosphine ligands has provided important information in relation to polymer dynamics, which will be described separately in a specialized polymer journal. Here, we report our results on the model system using the regular (non polymer-supported) phosphine ligands since they provide interesting new information on the coordination chemistry of rhodium and notably on the mechanism of ligand exchange involving both neutral and anionic bidentate ligands.

\section{Results}

(a) The phosphine double exchange process

In order to conveniently follow the double exchange reaction 1 by NMR spectrometry, we searched for a combination of two Rh systems and two phosphine ligands allowing us to individually detect all four compounds in the mixture, at least by the better resolved ${ }^{31} \mathrm{P}$ NMR technique. The suitable combination was identified as $[\mathrm{RhCl}(\mathrm{COD})(\mathrm{L})]$ and $[\mathrm{Rh}(\mathrm{acac})(\mathrm{CO})(\mathrm{L})]$ with $\mathrm{L}=\mathrm{PPh}_{3}$ and $\mathrm{P}\left(\mathrm{C}_{6} \mathrm{H}_{4}-4-\mathrm{OMe}\right)_{3}$. These ligands will be henceforth abbreviated as TPP for triphenylphosphine and TMOPP for tris(4methoxyphenyl)phosphine. The double exchange process in eq. 1 was investigated by mixing $[\mathrm{RhCl}(\mathrm{COD})(\mathrm{TPP})], \mathbf{1}$, and [Rh(acac)(CO)(TMOPP)], 2, in $\mathrm{CDCl}_{3}$. Relevant ${ }^{31} \mathrm{P}$ NMR spectra are collected in Figure 1. They demonstrate that the double phosphine exchange process is very rapid, an essentially equilibrated 1:1:1:1 mixture of the four compounds being obtained rapidly after mixing, spectrum (c). The observed chemical shifts and $J_{\text {PRh }}$ coupling constants for each compound are in agreement with those reported in the literature: $1, \delta 30.68, J_{P R h}=150.6 \mathrm{~Hz}$ (lit.: $\delta 31.3, \mathrm{~J}_{\mathrm{PRh}}=150.1 \mathrm{~Hz}$ ) ${ }^{[10]} ; \mathbf{2}, \delta 44.14, \mathrm{~J}_{\mathrm{PRh}}=173.7 \mathrm{~Hz}$ (lit.: $\delta$ 43.5, JPRh $=175.6 \mathrm{~Hz})^{[11]}$; [Rh(acac)(CO)(TPP)] (3), $\delta 48.67$, JPRh $=175.0 \mathrm{~Hz}$ (lit.: $\delta 48.6, \mathrm{~J}_{\mathrm{PRh}}=179.7 \mathrm{~Hz}{ }^{[12]}$; [RhCl(COD)(TMOPP)] (4), $\delta 27.00, J_{P R h}=149.4 \mathrm{~Hz}$ (lit:: $\left.\delta 27.7, J_{P R h}=148.7 \mathrm{~Hz}\right){ }^{[10]}$ Additional resonances, however, are already visible after $30 \mathrm{~min}$ in the $\delta 32-23$ region and increased slowly, indicating the formation of additional products. 


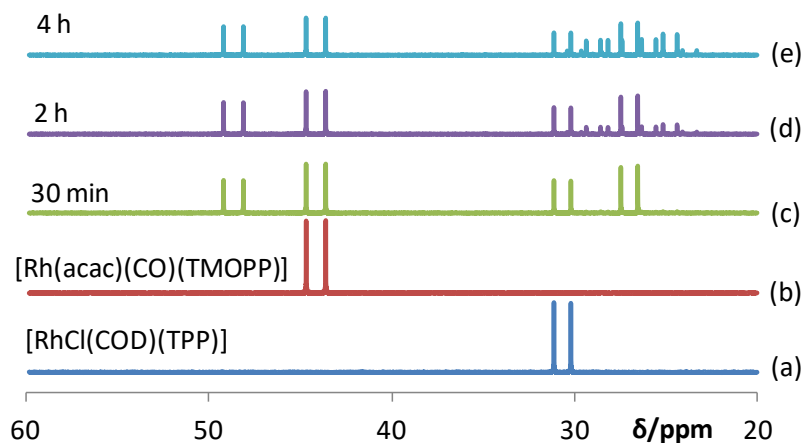

Figure 1. ${ }^{31} \mathrm{P}\left\{{ }^{1} \mathrm{H}\right\}$ NMR spectra recorded related to the reaction between [RhCl(COD)(TPP)], 1, and [Rh(acac)(CO)(TMOPP)], 2, solvent $=\mathrm{CDCl}_{3}$, room temperature. (a) complex 1; (b) complex 2; (c-e), 1:1 mixture, spectra recorded after the indicated time from mixing.

Further evolution of the mixture at room temperature led to the essentially complete disappearance of the resonances of the four above-mentioned complexes, indicating the irreversibility of the process. Crystallization of the final solution by pentane vapour diffusion led to the deposition of a crystalline solid that, after redissolution into $\mathrm{CDCl}_{3}$, afforded the ${ }^{31} \mathrm{P}\left\{{ }^{1} \mathrm{H}\right\}$ NMR spectrum shown in Figure 2. Subsequent P-P COSY and P-Rh HMQC and HSQC analyses (see Supporting Information, Figures S1-S3) indicated that the mixture consists of three different compounds: one (5) with $\delta\left({ }^{31} \mathrm{P}\right)=28.97, \delta\left({ }^{103} \mathrm{Rh}\right)=-8169$ and $\mathrm{J}_{\mathrm{PRh}}=124.7 \mathrm{~Hz}$, a second one $(6)$ with $\delta\left({ }^{31} \mathrm{P}\right)=24.76, \delta\left({ }^{103} \mathrm{Rh}\right)=-8149$ and $\mathrm{JPRh}_{\mathrm{PR}}=$ $123.9 \mathrm{~Hz}$, and a third one (7) characterized by an $A B X\left(P_{2} R h\right)$ system in the ${ }^{31} \mathrm{P}$ spectrum with $\delta_{1}\left({ }^{31} \mathrm{P}\right)=29.90, \delta_{2}\left({ }^{31} \mathrm{P}\right)=24.82$, $\delta\left({ }^{103} \mathrm{Rh}\right)=-8159, \mathrm{~J}_{\mathrm{P} 1 \mathrm{Rh}}=125.0 \mathrm{~Hz}, \mathrm{~J}_{\mathrm{P} 2 \mathrm{Rh}}=126.5 \mathrm{~Hz}$ and $\mathrm{J}_{\mathrm{P} 1 \mathrm{P} 2}=$ $361.3 \mathrm{~Hz}$.

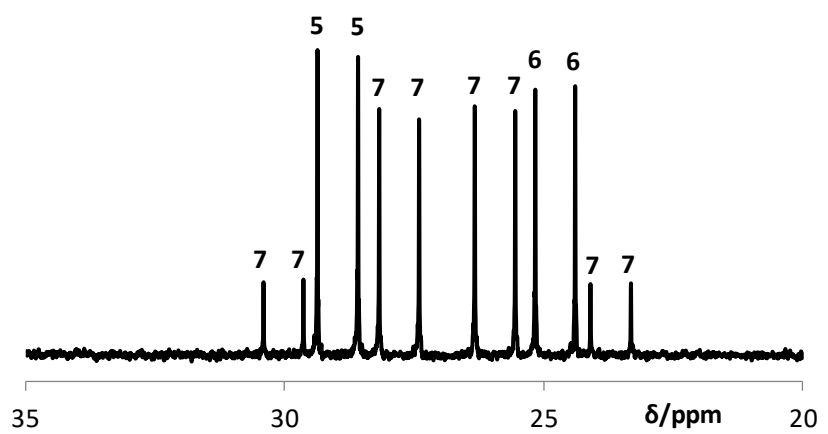

Figure 2. ${ }^{31} \mathrm{P}\left\{{ }^{1} \mathrm{H}\right\}$ NMR spectrum $\left(\mathrm{CDCl}_{3}\right)$ of the solid crystallized after the complete reaction between 1 and 2 .

\section{(b) Simpler exchange processes on Rh complexes}

In order to determine the precise nature of products 5, $\mathbf{6}$ and 7 , additional experiments were carried out by mixing, on one hand, pairs of Rh complexes having the same ligand set except the phosphine (i.e. $\mathbf{1}$ and $\mathbf{4}$ and separately $\mathbf{2}$ and $\mathbf{3}$ ) and, on the other hand, pairs of Rh complexes having different ligand set and the same phosphine (i.e. $\mathbf{1}$ and $\mathbf{3}$ and separately $\mathbf{2}$ and $\mathbf{4}$ ). The former two experiments did not lead to any spectral evolution, whereas the latter ones led to the evolutions illustrated in Figure 3 and Figure 4. The reaction between 1 and 3 led selectively to the resonance of compound $\mathbf{5}$, whereas that between $\mathbf{2}$ and $\mathbf{4}$ led selectively to the resonance of compound $\mathbf{6}$. The formation of compound 5 (Figure 3 ) is already quantitative after mixing and immediately recording the spectrum, the resonance of 1 at $\delta$ 30.68 (Figure 1a) having completely disappeared. A small residual resonance of 3 at $\delta 48.67$ remains present because this compound was used in slight excess. The formation of compound 6 from 2 and $\mathbf{4}$ was much slower, since the resonances of both reagents are still visible at small intensity after $24 \mathrm{~h}$ (Figure 4b). Both 5 and 6 were isolated from the final mixtures by crystallization. Comparison with the literature ${ }^{[13-14]}$ indicated that they correspond to trans-[RhCl(CO)(TPP $\left.)_{2}\right]$ and trans$\left[\mathrm{RhCl}(\mathrm{CO})(\mathrm{TMOPP})_{2}\right]$, respectively. The identity of $\mathbf{6}$ was further confirmed by determination of the unit cell parameters of a single crystal, which matched with those reported for $\left[\mathrm{RhCl}(\mathrm{CO})(\mathrm{TMOPP})_{2}\right]^{[15]}$ The full spectral characterization of $\mathbf{5}$ and 6 (see SI) also included the ${ }^{13} \mathrm{C}\left\{{ }^{1} \mathrm{H}\right\} \mathrm{NMR}$, which has apparently not been previously reported. The carbonyl $C$ atom gives a complex multiplet, due to coupling to the ${ }^{103} \mathrm{Rh}$ and the two equivalent ${ }^{31} \mathrm{P}$ nuclei, around $\delta 187$ for both compounds but the spectra are distinguished by the different pattern for the aromatic $\mathrm{C}$ atoms and by the resonance of the $\mathrm{OMe} C$ atom at $\delta$ 55.4 for compound 6 .

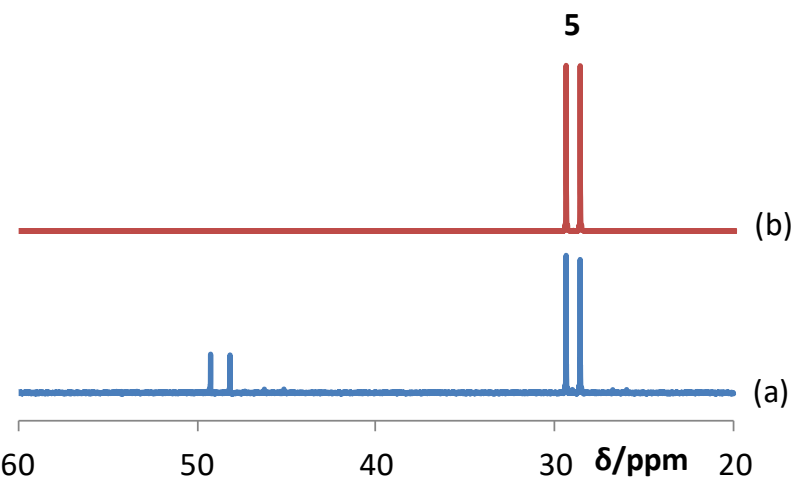

Figure 3. ${ }^{31} \mathrm{P}\left\{{ }^{1} \mathrm{H}\right\}$ NMR spectra recorded related to the reactions between $\mathbf{1}$ and 3. Solvent $=\mathrm{CDCl}_{3}$, room temperature. (a) immediately after mixing; (b) redissolved crystallized product.

The identification of the trans-[RhCl(CO) $\left.\mathrm{L}_{2}\right]$ products in these simpler experiments implies the simultaneous formation of [Rh(acac)(COD)] (8), equation 2 ( $L=$ TPP or TMOPP). Clearly, when the phosphine exchange is carried out on the mixture of both systems ( $L=$ TPP and TMOPP, as in Figure 1), the mixed phosphine derivative $[\mathrm{RhCl}(\mathrm{CO})(\mathrm{TPP})(\mathrm{TOMPP})]$ can also be generated by rapid phosphine exchange. This mixed phosphine complex must therefore correspond to product 7 (equation 3 ). 


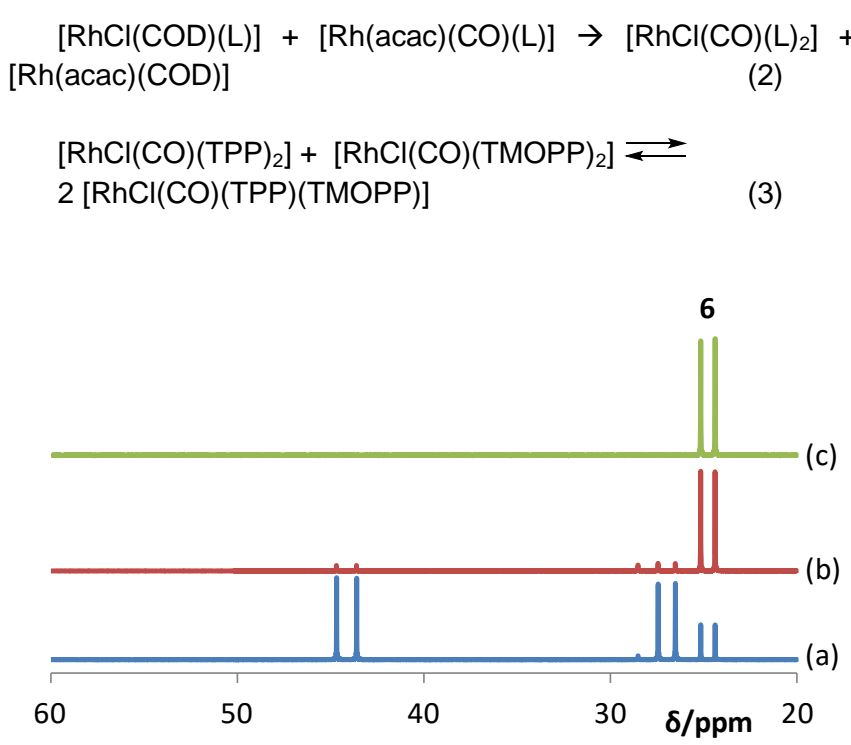

Figure 4. ${ }^{31} \mathrm{P}\left\{{ }^{1} \mathrm{H}\right\}$ NMR spectra recorded related to the reactions between 2 and 4. Solvent $=\mathrm{CDCl}_{3}$, room temperature. (a) Immediately; (b) after $24 \mathrm{~h}$; (c) redissolved crystallized product.
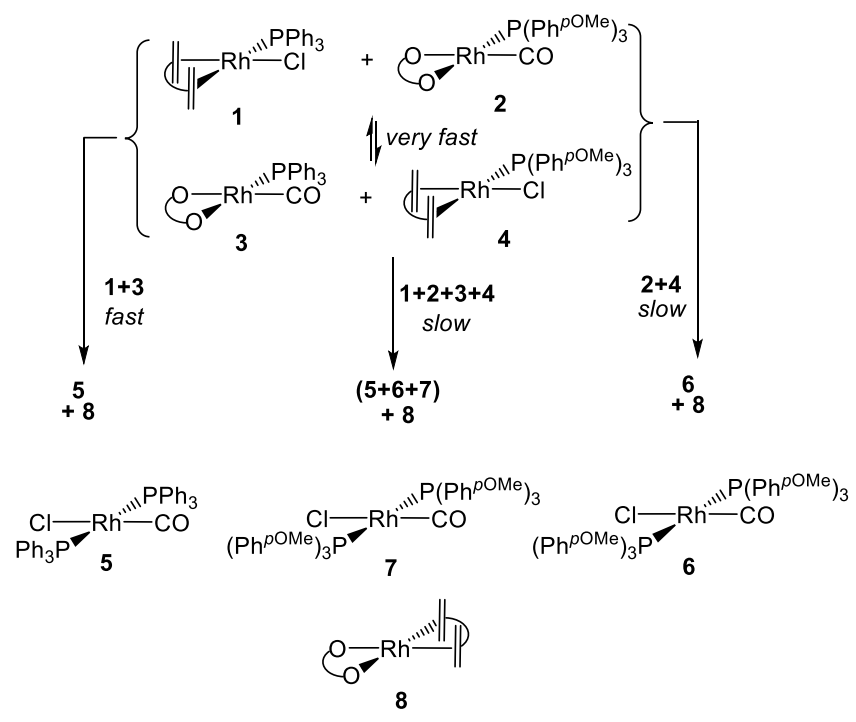

Scheme 1. Summary of the observed exchange processes.

The experimental study of this phenomenon was completed with the identification of the by-product $\mathbf{8}$. Since this compound is P-free, its detection could only rest on the ${ }^{1} \mathrm{H}$ and ${ }^{13} \mathrm{C} N M R$ properties. After removal of most of the less soluble $\left[\mathrm{RhCl}(\mathrm{CO})(\mathrm{L})_{2}\right]$ co-products by crystallization, the residual solution indeed exhibited spectra properties in agreement with those reported for $8 .{ }^{[16-17]}$ The observed ligand exchange processes can be summarized as shown in Scheme 1.

Several mixed phosphine complexes of type $\left[\mathrm{RhCl}(\mathrm{CO})\left(\mathrm{L}_{1}\right)\left(\mathrm{L}_{2}\right)\right]$, but not compound 7 , have previously been reported. Their ${ }^{31} \mathrm{P}$ NMR properties closely parallel those reported here for 7. They have been obtained, however, by phosphine exchange processes from $\left[\mathrm{RhCl}(\mathrm{CO})\left(\mathrm{L}_{1}\right)_{2}\right]$ and free $\mathrm{L}_{2}$, therefore only in a phosphine-rich environment. ${ }^{[18]}$ These reactions were described as very fast associative processes, whereas the process described here entails phosphine exchange from a $\mathrm{Rh}$ complex to another, accompanied by simultaneous rearrangement of the other ligands and notably bidentate ones. The exchange of bidentate ligands between two different $\mathrm{Rh}$ complexes has not been the subject of extensive investigations.

\section{(c) Ligand exchange between $\mathrm{Rh}$ and Ir complexes}

A final experiment consisted of running the same reaction as in equation $2(L=T P P)$ except that one complex contained $R h, 1$, whereas the other one contained $\operatorname{Ir}$, $[\operatorname{IrCl}(C O D)(T P P)]$ (9). The latter complex was generated in situ by adding one equivalent of TPP per Ir atom to compound $[\mathrm{IrCl}(\mathrm{COD})]_{2}$. This experiment was expected to lead to either the products of equation 4 or to those of equation 4', depending on the way in which the ligands are exchanged. Exchanging the neutral ligands ( $\mathrm{CO}$ and TPP on the $\mathrm{Rh}$ complex with COD on the Ir complex) yields the products of equation 4 , whereas exchanging the anionic ligands (acac on the Rh complex with $\mathrm{Cl}$ and TPP on the Ir complex) leads to the products of equation 4'. Thus, the results of this experiment provide useful information on the ligand exchange mechanism.

$$
\begin{array}{cc}
{[\operatorname{Rh}(\mathrm{acac})(\mathrm{CO})(\mathrm{TPP})]+[\operatorname{IrCl}(\mathrm{COD})(\mathrm{TPP})]} & \mathbf{9} \\
\mathbf{1} & \rightarrow \\
{[\mathrm{Rh}(\mathrm{acac})(\mathrm{COD})]} & +\left[\operatorname{IrCl}(\mathrm{CO})(\mathrm{TPP})_{2}\right] \\
\mathbf{8} & \mathbf{1 0} \\
{[\operatorname{Ir}(\mathrm{acac})(\mathrm{COD})]+} & {\left[\mathrm{RhCl}(\mathrm{CO})(\mathrm{TPP})_{2}\right]} \\
\mathbf{1 1} & \mathbf{5}
\end{array}
$$

The ${ }^{31} \mathrm{P}\left\{{ }^{1} \mathrm{H}\right\}$ NMR results of this experiment are shown in Figure 5. After $7 \mathrm{~h}$ at room temperature, the starting material resonances are still visible (doublet at $\delta 48.67$ with $J_{\mathrm{PRh}}=175.0$ $\mathrm{Hz}$ for 1 and singlet at $\delta 21.93$ for $\mathbf{9}$. However, a new singlet at $\delta$ 24.20 can be assigned to 10 , the expected phosphine-containing products of equation (4) (cf. lit. 23.40 in $\mathrm{CDCl}_{3}{ }^{[14]}$ ) and a new small doublet at $\delta 29.27\left(\mathrm{~J}_{\mathrm{RhP}}=126.8 \mathrm{~Hz}\right)$ can be assigned to 5 , the expected product of equation (4'). The integrated intensities of 10 and 5 are in a 2.8:1 ratio. The ${ }^{13} \mathrm{C}\left\{{ }^{1} \mathrm{H}\right\}$ spectrum confirmed the presence of both $\mathbf{8}^{[16-17]}$ and $11^{[19]}$ through the characteristic resonances of the metal-bonded COD carbon atoms: doublet at $\delta$ 76.24 (cf. 76.76) ${ }^{[16-17]}, \mathrm{J}_{\mathrm{CRh}}=14 \mathrm{~Hz}$ for 8 and singlet at $\delta 58.87$ (cf. $59.3)^{[19]}$ for 11. This spectrum is shown in the SI (Figure S4). The intensity of the 8 resonance is greater than that of $\mathbf{1 1}$ by a factor of 15.0. Since the reaction was carried out with equimolar amounts, the $10 / 5$ and $8 / 11$ ratios should be identical, but identical intensity ratios are not to be expected because the NMR integration for the Overhauser-enhanced resonances of the slowrelaxing ${ }^{31} \mathrm{P}\left\{{ }^{1} \mathrm{H}\right\}$ and ${ }^{13} \mathrm{C}\left\{{ }^{1} \mathrm{H}\right\}$ nuclei does not carry quantitative information. The proton environment of these nuclei in the two compounds should be rather similar, suggesting that the Overhauser effect may not be significantly different in each pair of related compounds. However, the relaxation times could be significantly different because in one case the observed nucleus is bonded to a magnetically dipolar ${ }^{103} \mathrm{Rh}$ nucleus, whereas in the 
other case it is bonded to a quadrupolar $(I=3 / 2)$ Ir nucleus. In order to reconcile the different observed intensities, we must consider that the resonance intensity of the $\mathrm{Rh}$ complex is underestimated relative to that of the Ir complex in at least one (but probably both) of the NMR spectra. At any rate, the two NMR measurements consistently indicate that the exchange proceeds preferentially through equation 4 by a factor bracketed by the lower $\left({ }^{31} \mathrm{P}\left\{{ }^{1} \mathrm{H}\right\}\right)$ and upper $\left({ }^{13} \mathrm{C}\left\{{ }^{1} \mathrm{H}\right\}\right)$ integrated intensity limits of 2.8 and $15.0 .{ }^{[20]}$

Hence, the reaction occurs through both mechanisms, but the neutral ligand exchange pathway prevails. It relevant to note that the exchange of $\mathrm{Cl}$ and acac ligands between different metals is not unprecedented, being reported for the exchange between various $\mathrm{M}(\mathrm{acac})_{2}$ and $\mathrm{M}^{\prime} \mathrm{Cl}_{2}$ complexes $\left(\mathrm{M}, \mathrm{M}^{\prime}=\mathrm{Mg}, \mathrm{V}, \mathrm{Fe}, \mathrm{Co}, \mathrm{Ni}\right.$, $\mathrm{Zn}, . .$.$) , leading in many cases to the observation of bimetallic$ intermediates. ${ }^{[21-23]}$

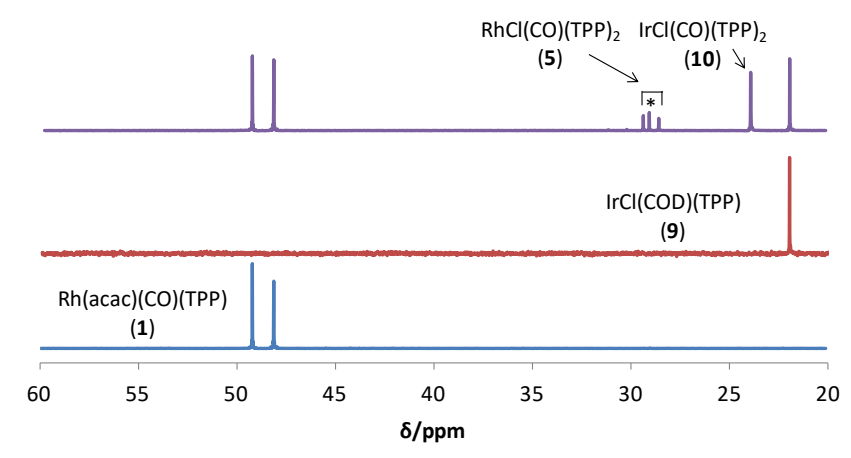

Figure $5 .{ }^{31} \mathrm{P}\left\{{ }^{1} \mathrm{H}\right\}$ NMR spectra related to the reaction between $\mathbf{1}$ (blue spectrum) and $\mathbf{9}$ (red spectrum). The violet spectrum was recorded $7 \mathrm{~h}$ after mixing. Solvent $=\mathrm{CD}_{2} \mathrm{Cl}_{2}$, room temperature. The starred resonance corresponds to a $\mathrm{Ph}_{3} \mathrm{PO}$ impurity.

\section{Discussion}

It is of interest to speculate on the mechanism of the slow bidentate ligand exchange processes of equations 2 and 4/4'. The redistribution, which will be represented for a generic phosphine ligand L, must involve either exchange of neutral ligands - a cyclooctadiene on the $\mathrm{M}$ complex, where $\mathrm{M}=\mathrm{Rh}$ for equation 2 or Ir for equations 4 and 4', with $\mathrm{L}$ and $\mathrm{CO}$ on the other $\mathrm{Rh}$ complex - or exchange of the anionic ligands - acac on the Rh complex with $\mathrm{Cl}$, accompanied by $\mathrm{L}$, on the $\mathrm{M}$ complex. In order to experimentally distinguish the two possibilities for the Rh-only system of equation 2, it would be necessary to carry out an isotope labelling experiment where the label is on the metal atom, which is impossible with naturally occurring isotopes because the metal is $100 \%{ }^{103} \mathrm{Rh}$. However, a related reaction where one compound was labelled using the Ir congener (equations 4 and 4 '), showed the occurrence of both exchange pathways. Obviously, this result only proves that the mixed metal system is able to follow both exchange pathways. The Rh-only system of equation 2 could undergo the slow bidentate ligand exchange by only one of the two possible schemes. However, it seems reasonable to extrapolate the result of the mixed-metal system to the Rh-only system. Importantly, the operating mechanism must be able to rationalize the large rate difference observed when $L=$ TPP or TMOPP.

We start by analyzing the "neutral ligand exchange" pathway. The system does not contain any free neutral ligand capable of triggering an associative exchange pathway, since the solvent chloroform has no significant coordinating properties. As mentioned in the introduction, ligand exchange processes in $\mathrm{Rh}^{\prime}$ complexes are generally associative, but a few examples where the metal reactivity (ligand exchange or other) is triggered by ligand dissociation exist, including dissociation of $\mathrm{N}_{2}$ trans to an aryl group ${ }^{[24]}$ and $\mathrm{SiPr}_{2}$ trans to an amido donor, ${ }^{[25]}$ The dynamic behaviour of complexes $\left[\mathrm{RhX}\left(\mathrm{PPh}_{3}\right)_{3}\right]\left(\mathrm{X}=\mathrm{Cl}, \mathrm{CF}_{3}, \mathrm{H}, \mathrm{CH}_{3}, \mathrm{Ph}\right)$ is a peculiar example of a dissociative self exchange process. ${ }^{[26]} \mathrm{All}$ these processes, however, deal with monodentate ligands.

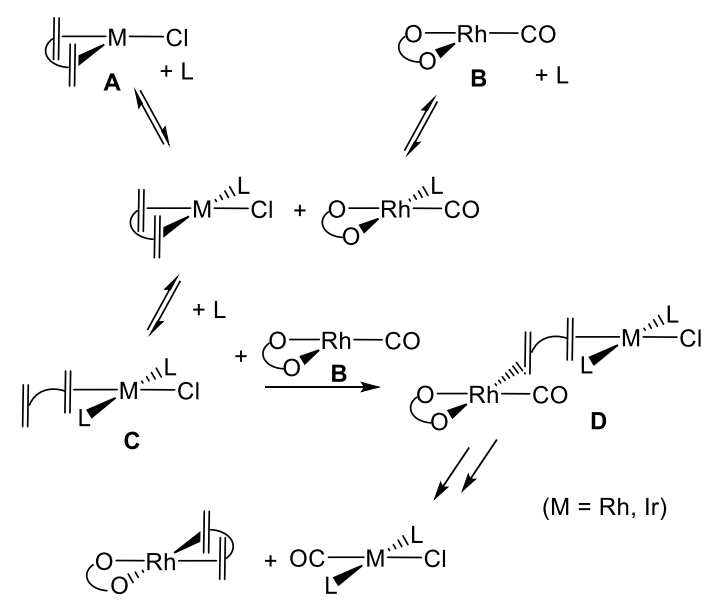

Scheme 2. Possible mechanism for the neutral ligand exchange leading from $[\mathrm{MCl}(\mathrm{COD}) \mathrm{L}]$ and $[\mathrm{Rh}(\mathrm{acac})(\mathrm{CO}) \mathrm{L}]$ to $[\mathrm{Rh}(\mathrm{acac})(\mathrm{COD})]$ and $\left[\mathrm{MCl}(\mathrm{CO}) \mathrm{L}_{2}\right](\mathrm{M}=$ $\mathrm{Rh}, \mathrm{Ir})$.

A reasonable dissociative pathway for the exchange of neutral ligands may be conceived a shown in Scheme 2. Given the known trends of trans effects, of ligand bond dissociation energies and of chelating effects, the most likely initial dissociation is that of $L$ trans to one of the COD double bonds in complex [RhCl(COD)L] yielding intermediate $\mathbf{A}$, but this process in unproductive. Dissociation of $\mathrm{L}$ trans to one acac $\mathrm{O}$ atoms in the other reaction partner yields intermediate B. Next, compound [RhCl(COD)(L)] may react with additional $L$, generated during the reversible formation of either $\mathbf{A}$ or $\mathbf{B}$, to open the COD chelate and yield intermediate $\mathbf{C}$, possibly via an associative pathway. This intermediate may then react with $\mathbf{B}$ to afford the COD-bridged bimetallic complex $\mathbf{D}$. There are many ways in which this exchange may further proceed to the final products, but the important points are the formation of the bimetallic intermediate and the initial dissociation of $\mathrm{L}$. On the basis of this hypothesis, the observed trend of reactivity (much faster rate when $L=$ TPP) appears consistent with the literature. Indeed, through calorimetric studies, Nolan et al. reported that the reaction between $[\mathrm{RhCl}(\mathrm{COD})]_{2}$ and $\mathrm{L}$ to yield $[\mathrm{RhCl}(\mathrm{COD}) \mathrm{L}]$ is more 
favourable for TMOPP $(58.7 \pm 0.3 \mathrm{kcal} / \mathrm{mol})$ than for TPP $(51.7 \pm 0.3$ $\mathrm{kcal} / \mathrm{mol}){ }^{[27]}$ Hence, the dissociation of TMOPP from $\mathrm{Rh}^{\prime}$ is expected to be much slower than that of TPP.

Turning now to the "anionic ligand exchange" pathway, it is clear that a dissociative process involving dissociation of the anionic ligands and charge separation would be difficult, especially in a low polarity solvent such as chloroform. An associative processes, however, seems feasible. It is also possible that the association via formation of bridged dinuclear intermediates is triggered by dissociation of a neutral ligand. This is suggested by the literature report of rapid halide scrambling between $\left[\mathrm{RhBr}(\mathrm{CO})(\mathrm{TPP})_{2}\right]$ and $\left[\mathrm{IrCl}(\mathrm{CO})(\mathrm{TPP})_{2}\right] \cdot{ }^{[18]}$ The dynamic exchange on the ${ }^{1} \mathrm{H}$ NMR timescale of the two inequivalent halves of the COD ligand in compound [RhCl(COD)L] $\left(\mathrm{L}=\mathrm{PPh}_{3}, \mathrm{AsPh}_{3}\right)$, which is kinetically second order in metal complex, might also involve halide-bridged intermediates. ${ }^{[5]}$ We can thus propose that the first step of the reaction between $[\mathrm{RhCl}(\mathrm{COD}) \mathrm{L}]$ and $[\mathrm{Rh}(\mathrm{acac})(\mathrm{CO}) \mathrm{L}]$ is formation of a dinuclear halide bridged complex ( $\mathbf{E}$ in Scheme 3 ) with elimination of a ketone group of the acetylacetonate, which rearranges to monodentate coordination. The associative pathway is shown in Scheme 3 , but the dissociative variant would of course lead to the same result. The alternative exchange (associative or dissociative) of a phosphine ligand, leading to a similar dinuclear complex E', seems also possible but would be unproductive. In order to satisfy first principles, all elementary steps envisaged for this "anionic ligand exchange" mechanism are such that they produce neutral systems (i.e. no charge separation) and maintain a square planar configuration around each $\mathrm{Rh}^{\prime}$ center in all intermediates. Although pentacoordination is possible in $\mathrm{Rh}^{\prime}$ chemistry, square planar complexes are preferred when potentially $\pi$ donor atoms such as $\mathrm{Cl}$ or $\mathrm{O}$ are present in the coordination sphere. Thus, in intermediate $\mathbf{E}$, for instance, the positive charge of the $\mathrm{Rh}$ atom on the left hand side is saturated by the covalent interaction with the bridging $\mathrm{Cl}$ atom, whereas the bond of this $\mathrm{Cl}$ atom to the $\mathrm{Rh}$ center at the right is dative. The charge of the $\mathrm{Rh}$ atom on the right hand side is saturated by the enolate of the monodentate acac ligand. In the next step, the $\mathrm{Cl}$ and acac ligand swap positions through an exchange reaction that involves attack of the $\mathrm{Rh}$ atom on the left hand side by the lone pair of the free acac carbonyl function, as suggested in Scheme 3, for a net charge change of zero and formation of intermediate $\mathbf{F}$. From here onward, it is easy to see how the exchange may continue, with either associative or dissociative processes, to complete the ligand exchange.

The $O$ atoms in $[\mathrm{Rh}(\mathrm{acac})(\mathrm{CO}) \mathrm{L}]$ are also centers of nucleophilic reactivity. Therefore, it is possible in principle to envisage another anionic ligand exchange pathway, starting with attack of a rhodium complex by one $O$ lone pair of the acac ligand in the second complex. However, compounds of type $[\mathrm{Rh}(\mathrm{acac})(\mathrm{CO}) \mathrm{L}]$ have been reported not to lead to coalescence of the asymmetric acac resonances, ${ }^{[28]}$ even upon warming, although the phenomenon is observed in the presence of excess L. ${ }^{[12]}$ This suggests that ligand exchange by self-association, if it occurs, is a slower process for $[\mathrm{Rh}(\mathrm{acac})(\mathrm{CO}) \mathrm{L}]$ than for $[\mathrm{RhCl}(\mathrm{COD}) \mathrm{L}]$.

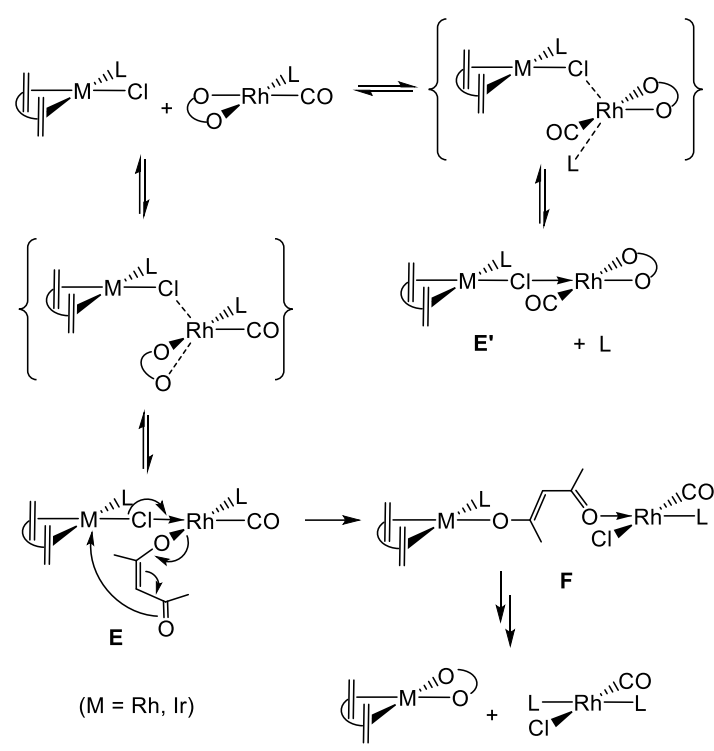

Scheme 3. Possible mechanism for the anionic ligand exchange leading from $[\mathrm{MCl}(\mathrm{COD}) \mathrm{L}]$ and $[\mathrm{Rh}(\mathrm{acac})(\mathrm{CO}) \mathrm{L}]$ to $[\mathrm{M}(\mathrm{acac})(\mathrm{COD})]$ and $\left[\mathrm{RhCl}(\mathrm{CO}) \mathrm{L}_{2}\right](\mathrm{M}=$ $\mathrm{Rh}, \mathrm{Ir})$.

Note that the first two exchange processes in the "anionic ligand exchange" pathway up to intermediate $\mathbf{F}$ do not involve $\mathrm{L}$ dissociation, therefore they do not account for the marked reactivity difference in rate when $L=T P P$ or TMOPP. $L$ dissociation only occurs in the further steps going from $\mathbf{F}$ to the products. Therefore, the pathway of Scheme 3 can be reconciled with the experimentally observed trend only if intermediate $\mathbf{F}$ is generated by fast pre-equilibrium processes, relative to the $L$ dissociation process which occurs in a later step and would be rate limiting.

Finally, it is necessary to comment on the difference in rate between equation (2) when $L=T P P$, which is very rapid as shown in Figure 3, and equations (4/4') where the ligand is again TPP, which is on the other hand much slower. This difference may be explained by the stronger Ir-ligand bonds relative to the corresponding Rh-ligand bonds. For the "neutral ligand exchange" pathway of Scheme 2, the initial TPP dissociation would not be discriminating since it always occurs on the Rh complex, but the COD dissociation step leading to intermediate $\mathbf{C}$ is likely much slower for the iridium complex. For the "anionic ligand exchange" pathway of Scheme 3, it is the Ir-TPP bond dissociating in one of the later rate-limiting steps that would make the difference in the observed exchange rates.

\section{Conclusion}

The rapid phosphine double exchange of equation 1, using the $\mathbf{1 / 2}$ combination, has unveiled an unexpected side reaction consisting of the slow exchange of the bidentate ligands, leading to the formation of $\mathbf{8}$ and a statistical mixture of $\mathbf{5 , 6}$ and $\mathbf{7}$. Control experiments involving the reactions between $[\mathrm{RhCl}(\mathrm{COD})(\mathrm{L})]$ and $[\mathrm{Rh}(\mathrm{acac})(\mathrm{CO})(\mathrm{L})]$ for $\mathrm{L}=\mathrm{TPP}$ or TMOPP, as well as involving the 
mixed-metal system 1 and $\mathbf{9}$ have provided useful information on the mechanism of this process. It has been demonstrated that both the neutral ligands (bidentate COD with $\mathrm{CO}$ and $\mathrm{L}$ ) and the anionic ligands (bidentate acac with $\mathrm{Cl}$ and $\mathrm{L}$ ) can be exchanged, at least for the mixed-metal system.

\section{Experimental Section}

General. All manipulations were performed under an inert atmosphere of dry argon by using vacuum line and Schlenk tube techniques. Acetylacetonatodicarbonylrhodium(I), $\left[\mathrm{Rh}(\mathrm{acac})(\mathrm{CO})_{2}\right] \quad(99 \% \quad$ Strem $)$, chloro(1,5-cyclooctadiene)rhodium(I) dimer, $[\mathrm{Rh}(\mathrm{COD}) \mathrm{Cl}]_{2}(98 \%$, Strem), chloro(1,5-cyclooctadiene)iridium(I) dimer, $[\operatorname{lr}(\mathrm{COD}) \mathrm{Cl}]_{2}(99 \%$, Strem), tris(4-methoxyphenyl)phosphine, TMOPP (>95\%, TCl), and triphenylphosphine, $\mathrm{PPh}_{3}(>98.5 \%$, Fluka) were used as received. Solvents were dried by standard procedures and distilled under argon prior to use. 1Dand 2D-NMR spectra were recorded in $5 \mathrm{~mm}$ tubes at $297 \mathrm{~K}$ with Bruker Avance 400 and 500 spectrometers. ${ }^{1} \mathrm{H}$ and ${ }^{13} \mathrm{C}$ chemical shifts were determined using the residual peak of deuterated solvent as internal standard and are reported in ppm $(\delta)$ relative to tetramethylsilane. ${ }^{31} \mathrm{P}$ chemical shifts are reported relative to external $85 \% \mathrm{H}_{3} \mathrm{PO}_{4}$. Peaks are labelled as singlet (s), doublet (d), triplet (t), multiplet (m) and broad (br). The proton and carbon assignments were assisted by ${ }^{1} \mathrm{H}-{ }^{13} \mathrm{C}$ HMQC experiments. Complexes $[\mathrm{RhCl}(\mathrm{COD})(\mathrm{TPP})],{ }^{[29]}[\mathrm{Rh}(\mathrm{acac})(\mathrm{CO})(\mathrm{TPP})],{ }^{[30]}$ $[\mathrm{Rh}(\mathrm{acac})(\mathrm{CO})(\mathrm{TMOPP})]^{[11]}$ and $[\mathrm{IrCl}(\mathrm{COD})(\mathrm{TPP})]^{[31]}$ were synthesized by procedures closely related to those reported in the literature (details in SI).

Isolation of a mixture of $\left[\mathrm{Rh}(\mathrm{CO}) \mathrm{Cl}(\mathrm{TPP})_{2}\right](5),\left[\mathrm{Rh}(\mathrm{CO}) \mathrm{Cl}(\mathrm{TMOPP})_{2}\right](6)$ and $[\mathrm{Rh}(\mathrm{CO}) \mathrm{Cl}(\mathrm{TPP})(\mathrm{TMOPP})]$ (7). The two separately prepared solutions of $2(35 \mathrm{mg}, 0.06 \mathrm{~mol})$ in $\mathrm{CH}_{2} \mathrm{Cl}_{2}(1 \mathrm{~mL})$ and 1 (30.5 mg, 0.06 $\mathrm{mmol})$ in $\mathrm{CH}_{2} \mathrm{Cl}_{2}(1 \mathrm{~mL})$ were combined at room temperature. The resulting mixture was stirred overnight. The resulting solution was concentrated to ca. half volume and then diffusion of pentane vapors yielded a crystalline solid. Yield $29 \mathrm{mg}$. The solid was characterized by ${ }^{31} \mathrm{P}\left\{{ }^{1} \mathrm{H}\right\}$ NMR (see Figure 2) and by ${ }^{31} \mathrm{P}_{-}{ }^{31} \mathrm{P}$ COSY, ${ }^{31} \mathrm{P}-{ }^{103} \mathrm{Rh}$ HMQC and ${ }^{31} \mathrm{P}-{ }^{103} \mathrm{Rh}$ HSQC (see $\mathrm{SI}$ ) in $\mathrm{CDCl}_{3}$.

Reaction between [RhCl(COD)(TPP)] (1) and [Rh(acac)(CO)(TPP)] (3): generation of $\left[\mathrm{Rh}(\mathrm{CO}) \mathrm{Cl}(\mathrm{TPP})_{2}\right]$ (5) and [Rh(acac)(COD)] (8). Two separately prepared solutions of $\mathbf{1}(30.5 \mathrm{mg}, 0.06 \mathrm{mmol})$ in $\mathrm{CH}_{2} \mathrm{Cl}_{2}(1.5$ $\mathrm{mL})$ and $3(29.5 \mathrm{mg}, 0.06 \mathrm{mmol})$ in $\mathrm{CH}_{2} \mathrm{Cl}_{2}(1.5 \mathrm{~mL})$ were combined and the resulting mixture was stirred at room temperature, progressively depositing a yellow precipitate. After $5 \mathrm{~h}$, the solid was filtered, washed with pentane and dried under vacuum. To the filtrate was added pentane $(20 \mathrm{~mL})$ to yield additional yellow crystalline precipitate, which was again filtered off, washed and dried. These solids were identified as 5 by NMR (see below) in comparison with the literature. ${ }^{[13]}$ The residual yellow solution was evaporated under reduced pressure to yield a yellow-brown solid, identified by NMR as 8 by comparison of its ${ }^{1} \mathrm{H}$ and ${ }^{13} \mathrm{C}\left\{{ }^{1} \mathrm{H}\right\}$ NMR spectra (see below) with the literature. ${ }^{[16-17]}\left[\mathbf{R h}(\mathrm{CO}) \mathrm{Cl}(\mathrm{TPP})_{2}\right]:{ }^{1} \mathrm{H}$ NMR (400 MHz, $\left.\mathrm{CDCl}_{3}\right)$ : $\delta$ 7.78-7.74 (m, 6H, CHAr), 7.44-7.4 (m, 9H, CHAr); ${ }^{31} \mathrm{P}\left\{{ }^{1} \mathrm{H}\right\}$ NMR $\left(162 \mathrm{MHz}, \mathrm{CDCl}_{3}, 298 \mathrm{~K}\right): \delta 28.97(\mathrm{~d}, \mathrm{JP}-\mathrm{Rh}=126.4 \mathrm{~Hz})$; ${ }^{13} \mathrm{C}\left\{{ }^{1} \mathrm{H}\right\}$ NMR (101.5 MHz, CDCl $)$ ): $\delta$ 187.6-186.6 (m, CO), 134.73, 132.96, 130.09, 128.12 ( $\left.\mathrm{CH}_{\mathrm{Ar}}\right)$. [Rh(acac)(COD)]: ${ }^{1} \mathrm{H}$ NMR $\left(400 \mathrm{MHz}, \mathrm{CDCl}_{3}\right.$, 298K): $\delta 5.34$ (s, $1 \mathrm{H}, \mathrm{CH}_{\text {acac }}$ ), 4.09 (s, $\left.4 \mathrm{H}, \mathrm{CH}_{\mathrm{cod}}\right), 2.49-2.46\left(\mathrm{~m}, 4 \mathrm{H}, \mathrm{CH}_{2}\right.$ cod), 1.95 (s, 6H, $\left.\mathrm{CH}_{3 \text { acac }}\right), 1.87-1.81$ (m, $\left.4 \mathrm{H}, \mathrm{CH}_{2 \mathrm{cod}}\right) ;{ }^{13} \mathrm{C}\left\{{ }^{1} \mathrm{H}\right\} \mathrm{NMR}(101.5$ $\mathrm{MHz}, \mathrm{CDCl}_{3}, 298 \mathrm{~K}$ ): $\delta 186.64$ (s, COacac), 134.8-134.4, 131.2-131.9, 130.24, 128.49, $128\left(\mathrm{CH}_{\mathrm{Ar}}\right), 99.76\left(\mathrm{~d}, \mathrm{~J}=2.03 \mathrm{~Hz}, \mathrm{CH}_{\mathrm{acac}}\right), 76.47$ (d, J = $14.7 \mathrm{~Hz}, \mathrm{CH}_{\mathrm{cod}}$ ), 30.24 (s, $\left.\mathrm{CH}_{2 \mathrm{cod}}\right), 27.36$ (s, $\mathrm{CH}_{3} \mathrm{acac}$ ).

Reaction between [RhCl(COD)(TMOPP)] (4) and [Rh(acac)(CO)(TMOPP)] (2): generation of $\left[\mathrm{Rh}(\mathrm{CO}) \mathrm{Cl}(\mathrm{TMOPP})_{2}\right]$ (6) and
[Rh(acac)(COD)] (8). This reaction was carried out according to the same protocol described in the previous section for the corresponding TPP complexes, starting from 2 (34.9 mg, $0.06 \mathrm{mmol})$ in $\mathrm{CH}_{2} \mathrm{Cl}_{2}(1.5 \mathrm{~mL})$ and 4 $(0.06 \mathrm{mmol})$ in $\mathrm{CH}_{2} \mathrm{Cl}_{2}(1.5 \mathrm{~mL})$. The latter was generated in situ from $\left[\mathrm{Rh}(\mathrm{COD}) \mathrm{Cl}_{2}(14.8 \mathrm{mg}, 0.03 \mathrm{mmol})\right.$ and TMOPP $(21.14 \mathrm{mg}, 0.06 \mathrm{mmol})$. The recovered yellow precipitate (same work-up as above) was identified as 6 by comparison of its NMR properties with the literature, ${ }^{[14]}$ while the residue recovered from the solution corresponded again to 8 . $[\mathbf{R h}(\mathbf{C O}) \mathbf{C l}-$ (TMOPP) ${ }_{2}$ ]: ${ }^{1} \mathrm{H}$ NMR $\left(400 \mathrm{MHz}, \mathrm{CDCl}_{3}\right): \delta 7.67-7.62\left(\mathrm{~m}, 6 \mathrm{H}, \mathrm{CH}_{\mathrm{Ar}}\right), 6.92$ (d, 6H, CH Arr ), $3.83\left(\mathrm{~s}, 9 \mathrm{H}, \mathrm{CH}_{3 \mathrm{OMe}}\right) ;{ }^{31} \mathrm{P}\left\{{ }^{1} \mathrm{H}\right\} \mathrm{NMR}\left(162 \mathrm{MHz}, \mathrm{CDCl}_{3}, 298 \mathrm{~K}\right)$ : $\delta 24.8$ (d, JP-Rh $=124.74 \mathrm{~Hz}) ;{ }^{13} \mathrm{C}\left\{{ }^{1} \mathrm{H}\right\}$ NMR $\left(101.5 \mathrm{MHz}, \mathrm{CDCl}_{3}\right): \delta 187.2$ $(\mathrm{m}, \mathrm{CO}), 160.86\left(C^{q}\right), 136.09\left(\mathrm{CH}_{\mathrm{Ar}}\right), 124.89\left(C^{q}\right), 113.7\left(\mathrm{CH}_{\mathrm{Ar}}\right), 55.4\left(\mathrm{CH}_{3}\right.$ $\mathrm{OMe}$ ). In addition, a single crystal of this compound was obtained from a dichloromethane solution by pentane vapor diffusion at room temperature. Its unit cell parameters correspond to those for the published structure of $\left[\mathrm{Rh}(\mathrm{CO}) \mathrm{Cl}(\mathrm{TMOPP})_{2}\right]^{[15]}$

Supporting Information (see footnote on the first page of this article): Synthetic protocols and NMR spectra as specified in the text (4 pages).

\section{Acknowledgements}

We are grateful to the Agence Nationale de la Recherche (ANR) for support of this work through grant "BIPHASNANOCAT" (ANR11-BS07-025-01). Additional support from the Centre National de la Recherche Scientifique (CNRS) and from the Institut Universitaire de France (IUF) is also gratefully acknowledged. We thank Dr. Y. Coppel for useful discussion of the NMR results.

Keywords: Rhodium • ligand exchange $\cdot$ acetylacetonate $•$ cyclooctadiene $\cdot$ phosphine ligands

[1] F. Basolo, R. G. Pearson, Mechanisms of Inorganic Reactions, John Wiley and Sons, Inc., New York, 1958.

[2] F. Basolo, in Advances in Chemistry Series, Vol. 49 (Ed.: R. F. Gould), American Chemical Society, Washington, D.C., 1965.

[3] J. D. Atwood, Inorganic and Organometallic Reaction Mechanisms, Brooks/Cole Publishing Co., Monterey, CA, 1985.

[4] C. A. Tolman, Chem. Soc. Rev. 1972, 1, 337-353.

[5] K. Vrieze, H. C. Volger, A. P. Praat, J. Organometal. Chem. 1968, 14, 185-200.

[6] E. Kwaskowska-Chęć, A. M. Trzeciak, J. J. Ziolkowski, React. Kinet Catal. Lett. 1984, 26, 21-24.

[7] A. F. Cardozo, E. Manoury, C. Julcour, J.-F. Blanco, H. Delmas, F. Gayet, R. Poli, ChemCatChem 2013, 5, 1161-1169.

[8] A. F. Cardozo, E. Manoury, C. Julcour, J.-F. Blanco, H. Delmas, F. Gayet, R. Poli, Dalton Trans. 2013, 42, 9148-9156.

[9] X. Zhang, A. F. Cardozo, S. Chen, W. Zhang, C. Julcour, M. Lansalot, J.-F. Blanco, F. Gayet, H. Delmas, B. Charleux, E. Manoury, F. D'Agosto, R. Poli, Chem. Eur. J. DOI: 10.1002/chem.201403819.

[10] J. Tiburcio, S. Bernes, H. Torrens, Polyhedron 2006, 25, 1549-1554.

[11] F. P. Pruchnik, P. Smolenski, K. Wajda-Hermanowicz, J. Organomet. Chem. 1998, 570, 63-69.

[12] A. M. Trzeciak, M. Jon, J. J. Ziolkowski, React. Kinet. Catal. Lett. 1982 20, 383-387.

[13] B. E. Mann, C. Masters, B. L. Shaw, J. Chem. Soc. A 1971, 1104-1106. 
[14] C. Rueger, A. Mehlhorn, K. Schwetlick, Z. Chem. 1974, 14, 196-197.

[15] S. Warsink, A. Roodt, Acta Crystallogr., Sect. E Struct. Rep. Online 2011, 67, m1695-m1696.

[16] W. A. Carole, T. J. Colacot, e-EROS Encyclopedia of Reagents for Organic Synthesis 2011.

[17] Z. B. Duan, M. J. Hampdensmith, E. N. Duesler, A. L. Rheingold, Polyhedron 1994, 13, 609-623.

[18] P. E. Garrou, G. E. Hartwell, Inorg. Chem. 1976, 15, 646-650.

[19] R. Bonnaire, N. Platzer, J. Organomet. Chem. 1976, 104, 107-116.

[20] The ${ }^{31} \mathrm{P}\left\{{ }^{1} \mathrm{H}\right\}$ and ${ }^{13} \mathrm{C}\left\{{ }^{1} \mathrm{H}\right\}$ spectra were recorded with standard parameters of acquisition time and relaxation delay. More quantitative information on the compound ratios could be obtained through use of coupled spectra (or gated decoupling conditions) and increased relaxation delays. However, the additional effort involved would not change the qualitative conclusion of this study. It would be fully justified for a more detailed kinetics investigation.

[21] M. Doring, H. Gorls, E. Uhlig, K. Brodersen, L. Dahlenburg, A. Wolski, Z. Anorg. Allg. Chem. 1992, 614, 65-72.
[22] M. Doring, E. Uhlig, K. Brodersen, A. Wolski, Z. Anorg. Allg. Chem. 1993, 619, 753-760.

[23] E. Solari, S. Deangelis, C. Floriani, A. Chiesivilla, C. Guastini, Inorg. Chem. 1992, 31, 141-144.

[24] R. Cohen, B. Rybtchinski, M. Gandelman, H. Rozenberg, J. M. L. Martin, D. Milstein, J. Am. Chem. Soc. 2003, 125, 6532-6546.

[25] S. Gatard, C. Guo, B. M. Foxman, O. V. Ozerov, Organometallics 2007 , 26, 6066-6075.

[26] J. Goodman, V. V. Grushin, R. B. Larichev, S. A. Macgregor, W. J. Marshall, D. C. Roe, J. Am. Chem. Soc. 2010, 132, 12013-12026.

[27] S. Serron, S. P. Nolan, K. G. Moloy, Organometallics 1996, 15, 4301 4306.

[28] A. M. Trzeciak, J. J. Ziolkowski, Inorg. Chim. Acta 1985, 96, 15-20.

[29] J. Chatt, L. M. Venanzi, J. Chem. Soc. 1957, 4735-4741.

[30] F. Bonati, G. Wilkinson, J. Chem. Soc. 1964, 3156-3160.

[31] R. H. Crabtree, G. E. Morris, J. Organomet. Chem. 1977, 135, 395-403. 


\section{Entry for the Table of Contents}

\section{FULL PAPER}

Complexes $\left[\mathrm{Rh}(\operatorname{acac})(\mathrm{CO})\left(\mathrm{L}^{1}\right)\right]$ and $\left[\mathrm{RhCl}(\mathrm{COD})\left(\mathrm{L}^{2}\right)\right]$ undergo a very rapid double exchange of the monodentate phosphine ligands followed by much slower exchange process involving the bidentate ligands.

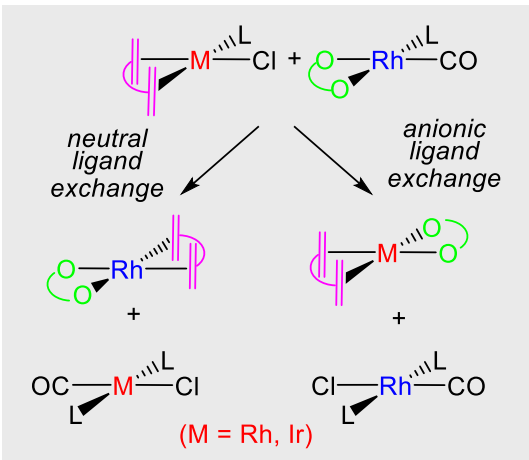

Si Chen, Eric Manoury, Rinaldo Poli*

Page No. - Page No.

Slow exchange of bidentate ligands between rhodium(I) complexes: evidence of both neutral and anionic ligand exchange 